\title{
Gestão compartilhada em áreas não metropolitanas: microrregiões
}

\author{
Shared management in non-metropolitan areas: microregions \\ Gestión compartida en áreas no metropolitanas: microrregiones
}

Recebido: 16/01/2022 | Revisado: 20/01/2022 | Aceito: 21/01/2022 | Publicado: 23/01/2022

\author{
Marinalva dos Reis Batista \\ ORCID: https://orcid.org/0000-0003-3308-5613 \\ Universidade Estadual de Maringá, Brasil \\ E-mail: Marinalva_mrb@hotmail.com \\ Angela Maria Endlich \\ ORCID: https://orcid.org/0000-0001-5203-5828 \\ Universidade Estadual de Maringá, Brasil \\ E-mail: amendlich@uem.br
}

\begin{abstract}
Resumo
Este trabalho apresenta uma breve explanação sobre o uso exagerado da figura da Região Metropolitana no Brasil. Esse uso apenas figurativo, pois de fato poucas devem ser consideradas como tal. Inclusive, tendo chances de ser revisto a formalização como Região Metropolitana. O próprio Estatuto da Metrópole traz opções como as aglomerações urbanas e as microrregiões como formas de gestão em detrimento as Região Metropolitanas. Esse fato deixa lacunas a serem preenchidas como a possibilidade de as microrregiões tornarem-se escala de gestão. Como muito aportes no Estatuto da Metrópole não vem esclarecido, toma-se como intuito investigar se as microrregiões atuais correspondem a proposta do Estatuto da Metrópole. Para a elaboração do presente trabalho realizou-se pesquisa bibliográfica e coleta de dados secundários sobre as comarcas na Espanha e sobra as microrregiões no estado do Paraná-Brasil. A gestão compartilhada pode preencher as lacunas da política territorial no Paraná e no Brasil, desde que bem estruturados priorizando as demandas de cada município ou de cada associação de municípios.
\end{abstract}

Palavras-chave: Municípios não metropolitanos; Associativismo Interfederativo; Pequenas localidades.

\begin{abstract}
This work presents a brief explanation about the exaggerated use of the figure of the Metropolitan Region in Brazil. This use is only figurative, for in fact few should be considered as such. Including the possibility of reviewing the formalization as a Metropolitan Region. The Metropolis Statute itself brings options such as urban agglomerations and micro-regions as forms of management to the detriment of the Metropolitan Region. This fact leaves gaps to be filled, such as the possibility of micro-regions becoming a management scale. As many contributions to the Metropolis Statute have not been clarified, the intention is to investigate whether the current microregions correspond to the proposal of the Metropolis Statute. For the elaboration of the present work, bibliographic research was carried out and secondary data collection was carried out on the regions in Spain and on the microregions in the state of Paraná-Brazil. Shared management can fill the gaps in territorial policy in Paraná and Brazil, provided that wellstructured, prioritizing the demands of each municipality or each association of municipalities.
\end{abstract}

Keywords: Non-metropolitan municipalities; Interfederative Associativism; Small localities.

\section{Resumen}

Este trabajo presenta una breve explicación sobre el uso exagerado de la figura de la Región Metropolitana en Brasil. Este uso es sólo figurativo, pues de hecho pocos deben ser considerados como tales. Incluyendo la posibilidad de revisar la formalización como Región Metropolitana. El propio Estatuto Metrópolis trae opciones como las aglomeraciones urbanas y las microrregiones como formas de gestión en detrimento de la Región Metropolitana. Este hecho deja vacíos por llenar, como la posibilidad de que las microrregiones se conviertan en una escala de gestión. Como no se han esclarecido muchas contribuciones al Estatuto de Metrópolis, la intención es investigar si las microrregiones actuales corresponden a la propuesta del Estatuto de Metrópolis. Para la elaboración del presente trabajo se realizó una investigación bibliográfica y una recolección de datos secundarios sobre las regiones en España y sobre las microrregiones en el estado de Paraná-Brasil La gestión compartida puede llenar los vacíos de la política territorial en Paraná y Brasil, siempre que esté bien estructurado, priorizando las demandas de cada municipio o de cada mancomunidad de municipios.

Palabras clave: Municipios no metropolitanos; Asociativismo Interfederativo; Pequeñas localidades. 


\section{Introdução}

A institucionalização de Regiões Metropolitanas tem marcado fortemente a realidade brasileira, desde as primeiras formalizadas na década de 1970. A criação de Regiões Metropolitanas tem suas expectativas exacerbadas, sobretudo porque mais de 87,3 milhões de pessoas vivem nessas regiões (Costa, 2011). Desse montante, também há muitos questionamentos, se são realmente metropolitanos todos os municípios que compõem as mais de 70 Regiões Metropolitanas existentes no Brasil, pois podem fazer parte, porém não participa da sua dinâmica metropolitana. Somente no Paraná há oito RMs, as quais abrangem 193 municípios.

Notadamente tem-se utilizado para os mais diversos arranjos essa forma de governança supramunicipal. A formalização exagerada de regiões metropolitanas no Brasil tem sido alvo de constantes debates no meio acadêmico, sobretudo porque o Estatuto da Metrópole, Lei no 13.089 de 12 de janeiro de 2015, aprovado após dez anos de trâmites no Senado Federal, traz outras figuras supramunicipais (microrregiões e aglomerados) para gerir as dinâmicas regionais e outras dubiedades como a classificação de metrópoles para se estabelecer uma Região Metropolitana-RM. Notadamente tem-se utilizado para os mais diversos arranjos essa forma de governança supramunicipal.

A formalização exagerada de regiões metropolitanas no Brasil tem sido alvo de constantes debates no meio acadêmico, sobretudo porque o Estatuto da Metrópole, Lei n ${ }^{\circ} 13.089$ de 12 de janeiro de 2015, aprovado após dez anos de trâmites no Senado Federal, traz outras figuras supramunicipais (microrregiões e aglomerados) para gerir as dinâmicas regionais e outras dubiedades como a classificação de metrópoles para se estabelecer uma Região Metropolitana-RM.

Isso significa que a figura da região metropolitana vem sendo priorizada para políticas territoriais em detrimento, por exemplo, de microrregiões e aglomerados urbanos, que são outras formas de unidades territoriais, e que seriam mais adequadas em determinados casos, como prevê o Estatuto da Metrópole (Lei n 13.089/2015).

Essa institucionalização exagerada de RMs, certamente, em conjunto com os processos operados pelo capitalismo, gera graves consequências, dentre elas, concentra ainda mais a população e o emprego de acordo com Lencioni (2006), Santos (2001), Firkowsk (2014), Endlich (2015), entre outros. Klink aponta que “Os problemas de governança metropolitana no cenário brasileiro não podem mais ser analisados em uma escala única, é necessária uma abordagem multiescalar, que reconhece as contradições geradas pela reestruturação do regime de organização" (Klink, 2001 p.85). Nesse sentido, a escala metropolitana tem-se mostrado como a escala mais duvidosa no cenário nacional.

\section{Metodologia}

Para a elaboração do presente trabalho realizou-se pesquisa bibliográfica e coleta de dados secundários sobre as comarcas na Espanha e sobra as microrregiões no estado do Paraná-Brasil.

\section{Resultados e Discussão}

As microrregiões do Estado do Paraná, propostas pelo IBGE (1990), foram baseadas num conjunto de determinações socioeconômicas, socioespaciais e também políticas. Tal divisão, baseada em dinâmicas similares, aproxima ainda mais os municípios sobre essa espacialidade e, assim, poderia tender para a gestão compartilhada. Porém, não se tem certeza se são essas microrregiões de que trata o Estatuto da Metrópole. O Estado do Paraná, a exemplo, é formado por 399 municípios, que se dividem em 39 microrregiões.

De acordo com IBGE (1990), as microrregiões foram definidas como partes das mesorregiões que apresentam especificidade referentes à estrutura de produção agropecuária, industrial, extrativismo mineral ou pesca. A organização se deu também pela vida de relações ao nível local, isto é, pela interação entre as áreas de produção e locais de beneficiamento e pela 
possibilidade de atender às populações através do comércio de varejo ou atacado ou dos setores sociais básicos. Assim, estrutura da produção para identificação das microrregiões é considerada em sentido totalizante constituindo-se pela produção propriamente dita, distribuição, troca e consumo, incluindo atividades urbanas e rurais.

Na metodologia operacional, o IBGE utilizou os seguintes parâmetros para identificação das mesorregiões: o processo social como determinante, o quadro natural como condicionante, rede de comunicação e de lugares como elemento da articulação espacial. Entre as etapas obteve-se: a) instrumental para o estudo dos processos sociais e das condicionantes do quadro natural; b) análise bibliográfica de textos sobre história social, povoamento e estudos geográficos; c) análise cartográfica do mapa isolado Atlas nacional, regional e estadual; d) análise de outras fontes de documentação específica. e) instrumental para o estudo da articulação espacial; f) análise de cartogramas sobre a área de influência dos centros metropolitanos e regionais; g) análise de mapas rodoviários do Departamento Nacional de Estradas de Rodagem - (DNER) e de comunicação e fluxograma de transporte quando houver.

Para a identificação das microrregiões foram selecionados dois indicadores básicos: o primeiro incide na estrutura da produção que implica na análise de estruturas da produção primária baseada na utilização da terra, orientação da agricultura, estrutura dimensional dos estabelecimentos, relação de produção, nível tecnológico e emprego de capital, e no grau de diversificação da produção agropecuária. O segundo indicador e a interação espacial ficam por conta da área de influência dos centros sub-regionais e centros de zona enquanto elementos articuladores dos processos de coleta, beneficiamento e expedição de produtos rurais de distribuição de bens e serviços ao campo e a outras cidades.

Essa metodologia do IBGE para criação das microrregiões, demonstra que essa divisão é bem fundamentada, o que falta para a divisão proposta em Regiões Metropolitanas (RMs). Para as microrregiões deve-se colocar em prática a gestão compartilhada já prevista na Constituição de 1988, no Estatuto da Cidade (2001) e no Estatuto da metrópole (2015), porém é preciso pensar em que tipo de intermunicipalidade seria definida, o que provavelmente, por sua natureza, seria decidido a partir de escalas superiores como as comarcas.

Em 2017, o IBGE apresentou nova proposta de Regiões Geográficas Imediatas e Regiões Geográficas Intermediárias (Figura 1), a Região Imediata tem em sua rede urbana seu principal elemento de referência: 


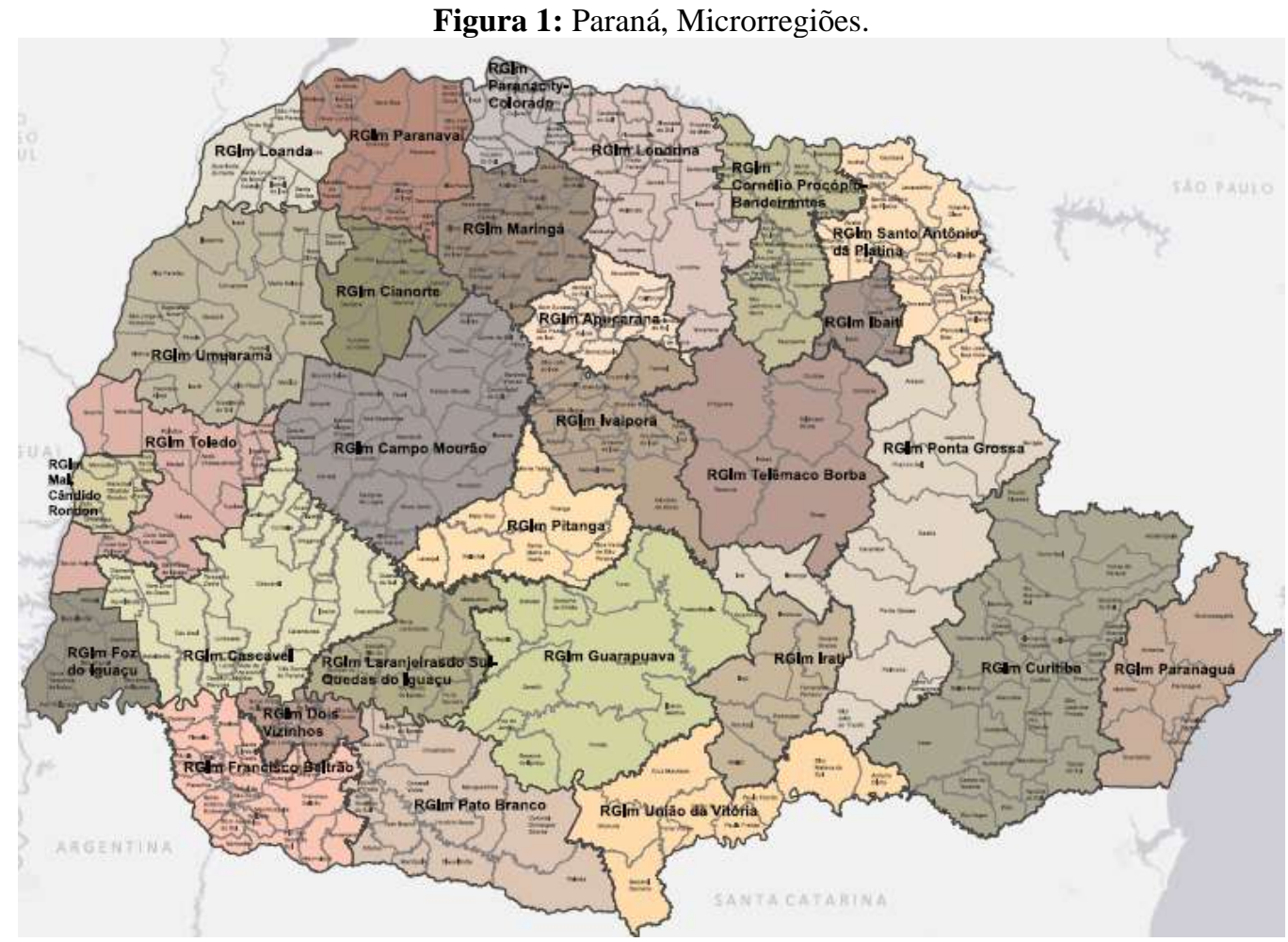

Fonte: IBGE (2017).

Essas regiões são estruturas a partir de centros urbanos próximos para a satisfação das necessidades imediatas das populações, tais como: compras de bens de consumo duráveis e não duráveis; busca de trabalho; procura por serviços de saúde e educação; e prestação de serviços públicos, como por atendimento do Instituto Nacional de Seguro Social - INSS, do Ministério do Trabalho e de serviços judiciários entre outros (IBGE, 2017, p. 20).

A Sedu (2017), por meio dos termos de referências para orientar a elaboração dos Planos de Desenvolvimento Urbano Integrado PDUIs no Paraná, trouxe uma abordagem das microrregiões como parte da gestão interfederativa. Nesses documentos foi Constatado, especialmente no volume III que se volta exclusivamente a essa figura institucional, que o território de cada uma das quatro Regiões Metropolitanas do Estado do Paraná deveria corresponder a uma microrregião.

Para tanto poderiam ser utilizados os recortes propostos anteriormente pelo IBGE como Microrregiões de Planejamento. Contudo, o documento busca outras formas de compartimentações existentes e consideradas como ativos institucionais que poderiam ser reconhecidas como microrregiões. Este é o caso das Associações de Municípios no Paraná: Associação dos Municípios da Região Metropolitana de Curitiba (Assomec), sede em Curitiba; Associação dos Municípios do Oeste do Paraná (Amop), sede em Cascavel; Associação dos Municípios do Médio Paranapanema (Amear), sede em Londrina; e Associação dos Municípios do Setentrião Paranaense (Amusep) sede em Maringá.

As microrregiões no Estatuto da Metrópole é "uma previsão de figura supramunicipal não metropolitana e que possa atender aos anseios desse conjunto de municípios que vêm reivindicando a formação de regiões metropolitanas, sem que possuam os atributos para assim serem consideradas" (Endlich, 2015, p. 8). A Constituição de 1988 gerou um modelo de gestão dos municípios em que os prefeitos são os atores fundamentais da dinâmica local e intergovernamental, o que acarretou em dificuldades para a resolução de alguns problemas mais abrangentes, como o microrregional, estadual, ou mesmo federal, provocando um isolamento dos municípios e dificuldades em pensar para além do território municipal, isto é, o supramunicipal.

De acordo com o Estatuto da Metrópole, a governança interfederativa é o compartilhamento de responsabilidades e 
ações entre entes da Federação em termos de organização, planejamento e execução de funções públicas de interesse comum. Nesse sentido, "as políticas públicas estariam vinculadas ao atendimento de demandas específicas, tendo como meta a maximização do bem-estar coletivo e a busca de patamares de equalização e justiça social" (Souza, 2006). A gestão compartilhada pode ser utilizada para atenuar as diferenças e torná-los mais próximos dos municípios com porte similar e com interações espaciais para fortalecê-los.

Existem novas propostas de alteração no Estatuto da Metrópole que incidem diretamente sobre as microrregiões. Foram apresentadas 31 propostas de alterações, classificadas em quatro categorias, sendo: i) alteração de texto, sem modificação de conteúdo; ii) adequação de texto às modificações propostas; iii) proposta de reflexão; e iv) alteração de conteúdo. A categoria "adequação de texto às modificações propostas" refere-se àquelas alterações que decorrem de mudanças de conteúdo propostas. Por exemplo: a proposta 1 sugere que o Estatuto da Metrópole seja aplicável também às microrregiões, impactando em diversos dispositivos cuja redação original menciona somente as RMs e as aglomerações urbanas (IPEA, 2018).

De acordo com o estudo do Ipea, algumas proposições foram classificadas em mais de uma categoria, por abrangerem mais de uma situação. As propostas 1 e 10 sugerem que o Estatuto da Metrópole contemple também as microrregiões, pois a Constituição Federal não fez distinção entre as diferentes unidades territoriais. As propostas 8 e 22 referem-se ao Plano Diretor de Desenvolvimento integrado (PDUI): tendo em vista que a subcomissão sugere que o estatuto seja aplicável também às microrregiões, inclusive rurais (não consta na proposta justificativa para essa inclusão, nem mesmo qual critério de "rural" foi utilizado pela comissão).

Ainda outra modificação que chama a atenção é a troca da expressão PDUI para Plano Regional de Desenvolvimento Integrado (PRDI), o que é mais coerente no que se objetiva com estabelecimento de diretrizes para o desenvolvimento regional, e não só no setor urbano. E, por fim, o PRDI deverá ser executado também em microrregiões, o que gera dúvidas e lacunas, pois não se sabe o perímetro dessas microrregiões e muitas estão nas áreas de regiões metropolitanas, como é o caso do estado do Paraná. Nesse sentido, se não forem bem elaboradas as próximas alterações ainda teremos as mesmas divergências ou poucas dúvidas serão sanadas.

Essas tentativas do Estatuto da Metrópole em estabelecer critérios para a gestão do território no Brasil ainda são muito incipientes, certo que deveria se tratar apenas das metrópoles, mas não o faz, inclui em sua redação as dimensões: aglomerados e as microrregiões. O que significa que esta lacuna existente no Estatuto da Metrópole deve ser pensada com muita cautela, isto porque, trata-se de estabelecer uma escala de gestão em que tenha viabilidade no ordenamento territorial.

Das instituições que trabalham com uma escala regional de gestão temos conhecimento das comarcas espanholas que têm tido algum êxito.

Os conflitos territoriais que culminam em regiões metropolitanas nos estados, configuram um processo que se iniciou na década de 1970 pretendendo uma política de desenvolvimento regional. Contudo, as leis, ainda incipientes, abordam a questão do ordenamento de forma superficial e pouco instrumentaliza essas regiões criadas. Os debates sobre metrópole e regiões metropolitanas se confundem e, assim, além dos dados populacionais, "é necessário analisar a cidade em sua interrelação com outras cidades de um determinado recorte espacial, e, nesse sentido, duas dimensões são fundamentais: a centralidade e a região de influência" (Firkowski, 2014, p. 23). De acordo com Fresca (2014), existem correntes teóricas que buscam a interpretação sobre a funcionalidade da metrópole que definiriam tal terminologia, enquanto outros autores ponderam os diversos aspectos da produção do espaço urbano nas áreas metropolitanas. De fato, o caráter conceitual da metrópole, de acordo com a autora, vincula-se ao poder econômico oriundo de diferentes atividades, passando historicamente pelo comércio regional, pela indústria e pelo sistema financeiro (Fresca, 2014, p. 19). 
Firkowski (2013) entende que a metrópole corresponde à cidade principal de uma região, aos nós de comando e coordenação de uma rede urbana que não só se destaca pelo tamanho populacional e econômico, como também pelo desempenho de funções complexas e diversificadas (Firkowski, 2013, p.34). Já a Região Metropolitana para Eros Grau (1975), corresponde a "um conjunto territorial intensamente urbanizado, com marcante densidade demográfica" (Grau, 1975, p. 25). Esse território se constitui como um polo de atividades econômicas, industriais e atividades intensas rurais, com dinamicidade própria definida por funções privadas e fluxos peculiares.

Entendemos que a metrópole extrapola o institucional. A Região Metropolitana é uma mera institucionalização. No entanto, houve e continua ocorrendo o uso exagerado dessa figura institucional no Paraná, bem como em outros estados. Além disso, há um exagero no número de municípios que foram vinculados a essas regiões metropolitanas e os problemas resultantes desta inclusão, como abordado por Batista (2017), tomando como exemplo, a Região Metropolitana de Maringá.

Essa dinâmica regional independente de ter se instalado ou não a Região Metropolitana permanece a mesma, em alguns casos acentua-se a dependência da cidade polo, isto porque, a grande parte dos municípios depende dos serviços e da demanda por mão de obra existente na cidade sede, o que significa que a dinâmica metropolitana é incipiente e a região metropolitana não respondeu concretamente suas metas de gestão compartilhada, o que significa a necessidade de novas modalidades de gestão compartilhada, ou ainda pensar em uma escala menor, ou seja, as microrregiões. O que até o momento não vem sendo pensada como escala de gestão. A proposta apenas aparece no Estatuto da Metrópole, entretanto, pouco desenvolvida.

No referido estatuto, fala-se das microrregiões como formas mais convenientes para agrupar municípios para a gestão compartilhada. Entretanto, não esclarece se teria uma nova divisão ou se seriam utilizadas as microrregiões já estabelecidas pelo Instituto Brasileiro de Geografia e Estatística.

O fato de o Estatuto da Metrópole trazer outras opções para gestão compartilhada significa que existe uma lacuna em política territorial no Brasil no que diz respeito as áreas não metropolitanas, do mesmo modo indica a necessidade de gestão compartilhada nestas áreas. De acordo com Monteiro (2002, p. 6) a Gestão Compartilhada "é aquela que sob variadas formas, articula diferentes tipos de gestão, criando novos canais de interação entre as pessoas, grupos, movimentos, organizações pertencentes à sociedade". Na mesma esteira, Ferreira expõe que a Gestão Compartilhada "busca superar obstáculos através da interação entre as forças sociais, políticas e culturais de uma determinada região, onde as diversas instâncias, agentes, programas e projetos formam um sistema integrado, compartilhado por todos" (Ferreira, 2006, p.35). De fato, a gestão compartilhada, seja em forma de consórcios, comarcas, mancomunidades, dentre outros, podem preencher as lacunas da política territorial no Paraná e no Brasil, desde que bem estruturados, priorizando as demandas de cada município ou de cada associação de municípios.

As microrregiões não dispõem de regulamentação, ou seja, não há definição de atribuições e competências específicas, entretanto, se assemelham às comarcas espanholas - agrupadas por critérios estabelecidos em instâncias superiores. As comarcas espanholas surgiram com interesse em formação de mercados secundários, entretanto, mais recentemente apresentam objetivos mais pontuais, tais como: transporte; proteção ambiental; agricultura; esporte; gestão industrial, dentre outros (Endlich, 2017). De acordo com Toscano Gil (2018, p. 05),

La decisión de crear una Comarca o un Área Metropolitana no responde habitualmente a una iniciativa de los Municipios afectados, sino del nivel de gobierno de ámbito territorial superior, la Comunidad Autónoma. Aunque los Municipios pueden oponerse a su creación en el caso de la Comarca, no ocurre así en el del Área Metropolitana, que se crea por ley del parlamento autonómico. Son entidades de constitución obligatoria, que responden a una potestad autonómica de coordinación de los Municipios afectados, no a una decisión de estos Municipios de cooperar entre sí. El Área Metropolitana se crea para la planificación conjunta y la coordinación de servicios y obras de grandes aglomeraciones urbanas, entre cuyos núcleos de población existan vinculaciones económicas y sociales que hagan 
necesaria esta coordinación. La Comarca se crea para gestionar interesses comunes o prestar servicios de ámbito comarcal.

As comarcas espanholas de acordo com Gutiérrez et al (2005) são definidas por leis específicas, as quais definem suas funções e competências, bem como a delimitação territorial. E os municípios podem escolher fazer parte ou não Toscano Gil (2018). As comarcas estão presentes nas comunidades de Aragon, Catalunha, Castela e Leão, Galícia e País Vasco na Espanha, todas instaladas entre 1986 a 1996. No quadro 01, observa-se que o número de iniciativas comarcais são mais expressivas na Galícia, Catalunha e Aragon todas com mais de 30 iniciativas comarcais, entretanto, a mais expressiva em número de municípios é a comunidade autônoma de Castela e Leão com 36 municípios em média na iniciativa e também a detém maior território com quase $3.000 \mathrm{Km}^{2}$. Já a mais expressiva em números populacionais é a comunidade autônoma da Galícia, com número médio de 6 municípios por comarca, mas com o maior número de municípios também, o que contribui para ser a maior em números populacionais com quase 500 mil habitantes.

Quadro 1: Comunidades de comarcas na Espanha, em 2005.

\begin{tabular}{|l|l|l|l|l|}
\hline $\begin{array}{l}\text { Comunidades } \\
\text { Autónomas }\end{array}$ & $\begin{array}{l}\mathrm{N}^{\circ} \text { de iniciativas de } \\
\text { comarcas }\end{array}$ & $\begin{array}{l}\mathrm{N}^{\circ} \text { médio de } \\
\text { municípios por } \\
\text { iniciativa }\end{array}$ & $\begin{array}{l}\text { População por } \\
\text { Iniciativa }\end{array}$ & $\begin{array}{l}\text { Superfície por } \\
\text { iniciativa (km2) }\end{array}$ \\
\hline Aragon & 33 & 21 & 36.398 & 1431.57 \\
\hline Catalunha & 41 & 23 & 154.713 & 787.63 \\
\hline Castela e Leão & 1 & 36 & 129.861 & 2997.42 \\
\hline Galícia & 53 & 6 & 498.542 & 553.34 \\
\hline País Vasco & 7 & 7 & 41.047 & 630.92 \\
\hline Total Espanha & 135 & 19 & 860.561 & 5845.00 \\
\hline
\end{tabular}

Fonte: Gutiérrez et al, 2005. *tradução do autor

Espanha, as experiências comarcais são consideradas como um intermédio entre a entidade municipal e a provinciana, o que permite mais alcances que as atuações municipais de forma independente.

No Brasil, as microrregiões (Quadro 2) são vistas como a compartimentação das mesorregiões. A área das microrregiões em sua maioria excede aos $2.000 \mathrm{Km}^{2}$, as que se destacam neste quesito é a microrregião de Guarapuava localizada na mesorregião centro sul com 16.115,00 $\mathrm{Km}^{2}$, a microrregião de Paranavaí e Umuarama com 10.182,50km² e 10.232,60, respectivamente, ambas localizadas na Mesorregião Noroeste.

A microrregião de Paranavaí ainda se destaca por abranger o maior número de municípios, com 29 no total, já Umuarama conta-se 21 municípios em sua microrregião. Porém, a microrregião de Curitiba é a que detém maior número de habitantes e sendo está a região mais dinâmica do estado que se distancia muito das demais por ter como característica a indústria como força motriz e as demais marcadas por uma dinâmica balizada pelos aparatos agrícolas.

Quadro 2: Microrregiões no Paraná-Brasil, em 2010.

\begin{tabular}{|l|l|l|l|}
\hline Microrregiões & $\begin{array}{l}\text { N }^{\circ} \text { de Municípios } \\
\text { por microrregião }\end{array}$ & População & Área \\
\hline Apucarana & 9 & 286.984 & $2.276,70$ \\
\hline Assaí & 8 & 71.173 & $2.238,70$ \\
\hline Astorga & 22 & 183.911 & $5.116,90$ \\
\hline Campo Mourão & 14 & 217.374 & $7.069,80$ \\
\hline Capanema & 8 & 95.292 & $2.317,30$ \\
\hline Cascavel & 18 & 432.978 & $8.515,90$ \\
\hline Cerro Azul & 3 & 29.041 & $3.472,00$ \\
\hline
\end{tabular}


Research, Society and Development, v. 11, n. 2, e23911225808, 2022

(CC BY 4.0) | ISSN 2525-3409 | DOI: http://dx.doi.org/10.33448/rsd-v11i2.25808

\begin{tabular}{|l|l|l|l|}
\hline Cianorte & 11 & 142.433 & $4.074,00$ \\
\hline Cornélio Procópio & 14 & 176.281 & $4.536,50$ \\
\hline Curitiba & 19 & 3.060 .332 & $8.541,20$ \\
\hline Faxinal & 7 & 46.358 & $2.265,00$ \\
\hline Floraí & 7 & 34.695 & $1.299,70$ \\
\hline Foz do Iguaçu & 11 & 408.800 & $5.579,90$ \\
\hline Francisco Beltrão & 19 & 242.411 & $5.451,50$ \\
\hline Goioerê & 11 & 116.751 & $4.865,70$ \\
\hline Guarapuava & 18 & 378.086 & $16.115,00$ \\
\hline Ibaiti & 8 & 77.359 & $3.034,30$ \\
\hline Irati & 4 & 97.449 & $2.834,10$ \\
\hline Ivaiporã & 15 & 137.649 & $6.154,30$ \\
\hline Jacarezinho & 6 & 122.552 & $2.755,90$ \\
\hline Jaguariaíva & 4 & 100.299 & $5.654,10$ \\
\hline Lapa & 2 & 49.446 & $2.280,40$ \\
\hline Londrina & 6 & 724.570 & $3.501,30$ \\
\hline Maringá & 5 & 540.477 & $1.573,20$ \\
\hline Palmas & 5 & 90.369 & $5.405,90$ \\
\hline Paranaguá & 7 & 265.392 & $6.057,20$ \\
\hline Paranavaí & 29 & 270.794 & $10.182,50$ \\
\hline Pato Branco & 10 & 159.424 & $3.883,10$ \\
\hline Pitanga & 6 & 75.735 & $4.904,60$ \\
\hline Ponta Grossa & 4 & 429.981 & $6.706,10$ \\
\hline Porecatu & 8 & 82.539 & $2.368,60$ \\
\hline Prudentópolis & 7 & 128.327 & $6.154,00$ \\
\hline Rio Negro & 6 & 89.531 & $2.474,00$ \\
\hline São Mateus do Sul & 3 & 62.312 & $2.532,80$ \\
\hline Telêmaco Borba & 6 & 158.999 & $9.489,80$ \\
\hline Toledo & 21 & 377.780 & $8.754,90$ \\
\hline Umuarama & 21 & 265.092 & $10.232,60$ \\
\hline União da Vitória & 7 & 116.691 & $5.485,70$ \\
\hline Wenceslau Braz & 10 & 98.859 & $3.161,20$ \\
\hline Total & & 10.444 .526 & $199.316,40$ \\
\hline & & & \\
\hline
\end{tabular}

Fonte: IBGE, (1990). IPEADATA, (2010).

De acordo com Vidigal et al. (2012), em uma análise das Microrregiões do Paraná, as microrregiões de Curitiba, Londrina e Maringá ocupam as primeiras colocações no ranking com as melhores condições de habitação e com maior densidade demográfica. As microrregiões de Paranaguá, Jaguariaíva, Floraí apresentam as piores condições de habitação e as menores densidades demográficas. No que se refere à questão econômica, as microrregiões de Paranaguá, Ponta Grossa e Jaguariaíva se mostraram em melhor estado no Paraná, enquanto as microrregiões de Cerro azul, Faxinal e Ivaiporã apresentaram as piores condições. Destaca-se a primeira posição para a microrregião de Paranaguá, na qual está presente o Porto Paranaguá, segundo maior porto brasileiro em movimentação de cargas e o maior complexo para embarque de granéis sólidos da América Latina (Vidigal et al. 2012).

Analisando os Quadros 1 e 2 observa-se que tanto as comarcas espanholas e as microrregiões não têm um número definido de municípios para comporem a área, todavia, como já destacamos antes, a metodologia do IBGE foi embasada nas similaridades entre os municípios e estarem próximos entre si. Nas comarcas os municípios também devem estar próximos e são estabelecidas para outros fins, como mencionado anteriormente. Essa modalidade abrange 2.064 municípios nas 135 iniciativas nas cinco comunidades autônomas, totalizando 860.561 habitantes em área das comarcas. Contrapondo com as microrregiões paranaenses, estas somam 10.444.526 habitantes, ou seja, toda a população do estado do Paraná, já que elas 
estão presentes em todo o território paranaense. A área média das microrregiões é em torno de $5.100,00 \mathrm{~km}^{2}$, o que chega bem perto do total de área de abrangência das comarcas na Espanha, que é de 5845,00 km².

As experiências na Espanha de acordo com Gutiérrez (2005), em Aragon, por exemplo, das iniciativas, destacam-se pelo planejamento do território e do urbanismo, meio ambiente e gestão de transportes. Em Castela e Leão destacam-se o planejamento territorial, planejamento urbano e saúde. Dentre outras iniciativas que são bem definidas por meio das leis que deram suas iniciativas. Nas microrregiões não há planos para esta escala, existe apenas os planos estaduais que, por consequência, atinge a área das microrregiões.

\section{Considerações Finais}

Neste estudo pretendeu-se apresentar uma breve contribuição acerca do tema microrregiões como proposta do Estatuto da Metrópole para gestão compartilhada em áreas não metropolitanas. Ainda, iniciamos um comparativo entre a ideia sinalizada no Estatuto da Metrópole de utilizar a figura das microrregiões como escala de gestão compartilhada e as comarcas espanholas, visando entender as similaridades e se há a possibilidade de usar como um exemplo a ser seguido pelas microrregiões. Contudo, será necessário buscar muitas outras experiências para apontar como um modelo possível de aplicação.

O Estatuto da Metrópole também não trouxe grandes esclarecimentos sobre como deveria ser essa unidade regional microrregião, gerando dúvidas entre os gestores municipais sobre quais e como deveriam ser incluídos novos municípios, e se realmente a institucionalização de uma região metropolitana é a melhor opção para propor a gestão compartilhada. A lei se intitula Estatuto da Metrópole, o que, seguramente, deveria tratar somente das metrópoles, todavia, não é o que a lei traz, pois também faz menção às microrregiões e aglomerados urbanos, mesmo que de modo insuficiente. Esse fato indica que a definição tem sido usada incorretamente e a própria lei indica alternativas além desta.

Ainda, analisando o Estatuto da Metrópole, do ponto de vista das pequenas localidades, nota-se que não há nenhuma menção a esses espaços. Este fator é no mínimo intrigante, pois as cidades com menos de 20 mil habitantes são um fenômeno numeroso no cenário brasileiro e, inclusive, nas regiões metropolitanas, e por sua escala as microrregiões estariam mais próximas às pequenas localidades. No referido estatuto, fala-se das microrregiões como formas mais convenientes para agrupar municípios para a gestão compartilhada. Entretanto, não esclarece se teria uma nova divisão ou se seriam utilizadas as microrregiões já estabelecidas pelo IBGE. Se já existe um padrão de subdivisão, a questão das regiões metropolitanas entra como um modismo no território brasileiro que cria novas unidades regionais sem ao menos ter desenvolvido plenamente as que já existem. Como já dito anteriormente, há novas mudanças propostas no Estatuto da Metrópole, no entanto, requer serem pensadas com mais cuidado, inclusive, sob a possibilidade de não reconhecer até mesmo as que já foram formalizadas.

O foco neste estudo são as microrregiões do Estado do Paraná propostas pelo IBGE, estas foram baseadas num conjunto de determinações socioeconômicas, socioespaciais e também políticas. Tal divisão, baseada em dinâmicas similares, aproxima ainda mais os municípios sob essa espacialidade e assim poderia tender para a gestão compartilhada com os recortes já estabelecidos e uma dinâmica que já lhe é própria, ou seja, gestão microrregional.

Nesse sentido, seguiremos a análise nas próximas legislações que forem referentes a escala de gestão microrregional, esperamos sejam mais elucidativas que as atuais.

\section{Agradecimentos}

Ao CNPq pela bolsa de estudos 
Research, Society and Development, v. 11, n. 2, e23911225808, 2022

(CC BY 4.0) | ISSN 2525-3409 | DOI: http://dx.doi.org/10.33448/rsd-v11i2.25808

\section{Referências}

Batista, M. R. (2017). Inserções e interações espaciais das pequenas localidades na Região Metropolitana de Maringá. (Dissertação de mestrado). UEM: Maringá, 2017.

Cruz, J. (2008). Os municípios se sublimam na metrópole: “ensaio sobre reforma metropolitana”. Recife: Cubzac.

Costa, Marco Aurélio (2013). Tsukumo, Isadora Tami Lemos (Orgs). 40 anos de regiões metropolitanas no Brasil. Brasília: Ipea.

Denardi, R. A. et al (2000). Fatores que afetam o desenvolvimento local em pequenos municípios do Estado do Paraná. Curitiba: Emater-PR.

Endlich, A. M. (2006). Pensando os papéis e significados das pequenas cidades do Noroeste do Paraná. Tese (doutorado) - Universidade Estadual Paulista, Faculdade de Ciências e Tecnologia. Presidente Prudente: Editora UNESP. 505 p.

Endlich, A. M. (2007). Gestão territorial compartilhada em espaços não-metropolitanos. Scripta Nova: revista electrónica de geografía y ciencias sociales, $(11), 62$.

Endlich, A. M. (2017). Cooperações intermunicipais: alguns aportes. Maringá: PGE-UEM. 139 p.

Endlich, A. M. (2015). Regiões metropolitanas do Paraná no divã: lacunas, entrelinhas e outras possibilidades de entes de gestão intermunicipal compartilhada. Bahia Análise e Dados, 25,343-357.

Ferreira, S. C. (2013). Dinâmica demográfica e cidades de porte médio na configuração da rede urbana do estado do paraná. In: Anais XIII Simpósio Nacional de Geografia Urbana - Simpurb. 2011. http://xiisimpurb2011.com.br.

Fresca, T. M. (2011). Uma discussão sobre o conceito de metrópole. Revista Anpege. 7(8), 31-52, ago./dez. <\&lt;www.anpege.org.br\&gt.

Firkowski, O. L. C. de F. (2014). Por que as Regiões Metropolitanas no Brasil são Regiões, mas não são metropolitanas. Http://www.ipardes.pr.gov.br.

Gonçalves JR, C. A. et al (2012). Análise diferencial/estrutural e fatorial do emprego nas microrregiões paranaenses entre 2005 a 2009 . Revista Paranaense de Desenvolvimento-RPD, (118), 41-66.

Grau, E. R. (2012). A ordem econômica na Constituição de 1988:(interpretação e crítica).

Instituto de Pesquisa Econômica Aplicada (2018). Brasil metropolitano em foco: desafios à implementação do Estatuto da Metrópole.

Instituto Brasileiro de Geografia e Estatística (1990). Mesorregiões e microrregiões. IBGE.

Instituto Brasileiro de Geografia e Estatística (2017). Divisão regional do Brasil em regiões geográficas imediatas e regiões geográficas intermediárias. Rio de Janeiro, Coordenação de Geografia. https://biblioteca.ibge.gov.br/visualizacao/livros/liv100600.pdf.

Paraná (2017). Secretaria de Estado do Desenvolvimento Urbano (Sedu); Serviço Social Autônomo (Paranacidade). Referências para a Política de Desenvolvimento Urbano e Regional para o Estado do Paraná. Curitiba.

Rodrigues Gutierrez, F.; Menendez Fernandez, R.; Cadernas Nevado, A. (2005). Comarcas, consorcios y otras experiencias innovadoras de cooperación territorial en España. Boletín de laasociación de geógrafos Españoles.

Klink, J (2001). A cidade-região - regionalismo e reestruturação no grande ABC paulista. DP\&A Editora.

Lencioni, S. (2006). Da cidade e sua região à cidade-região. In J. B. da Silva, L. C. Lima,D. Elias (Orgs.), Panorama da geografia brasileira. Annablume.

Lopez, M. A. (2014). La comarca como entidad natural, histórica y administrativa. Editorial Dykinson.

Santos, M. (2001). A Natureza do espaço. Técnica e Tempo, Razão e Emoção. (4.ed.) Hucitec,

Santos, M.; Silveira, M. L. (2002). O Brasil: território e sociedade no início do século XXI (2a ed.). Rio de Janeiro: Record.

Souza, C. et al (2006). Políticas públicas: uma revisão da literatura. Sociologias, 8(16), 20-45.

Vidigal, V. G., Castro I. A., Silveira, G. F. (2012). Desenvolvimento Socioeconômico nas microrregiões do Paraná: uma análise multivariada. Revista de Economia, 38(2) 